\title{
ASPECTOS CONCEITUAIS RELATIVOS AO CONSUMO DE CALOR NA PELOTIZAÇÃO DE MINÉRIO HEMATÍTICO *
}

José Murilo Mourão ${ }^{1}$

\section{Resumo}

A pelotização de minério de ferro hematítico demanda grande quantidade de calor para a produção de pelotas de boa qualidade. Avalia-se, neste trabalho, a quantidade teórica de calor, necessária para a queima de três tipos característicos de pelotas, e destacam-se pontos importantes do processamento de queima nos fornos de pelotização, no sentido de otimizar o consumo de calor..

Palavras-chave: Pelotização; Minério de Ferro; Hematita; Energia; Calor..

\section{CONCEPTUAL ASPECTS CONCERNING THE HEAT CONSUMPTION IN PELLETIZING OF HEMATITE ORE}

\section{Abstract}

The pelletizing of hematite iron ore demands large amount of heat for the production of good quality pellets. In this paper, it is evaluated the theoretical quantity of heat required for burning three types of pellets, and stand out important points of the firing in pelletizing kilns, in order to optimize the consumption of heat.

Keywords: Pelletizing; Iron Ore; Hematite; Energy; Heat.

1 Engenheiro Metalurgista, graduado pela Escola de Minas de Ouro Preto, em 1976, atualmente, atuando como Consultor Independente no campo mínero-siderúrgico, em Vitória ES, Brasil, e-mail: j-murilo@uol.com.br.. 


\section{INTRODUÇÃO}

A pelotização de minério de ferro hematítico (1) é uma atividade intensiva em consumo de energia, seja elétrica, seja térmica (calor). Para a obtenção de pelotas de boa qualidade, as pelotas cruas necessitam ser aquecidas a temperaturas médias da ordem de 1300 oC, de forma que várias reações físico-químicas ocorram e a consolidação do aglomerado seja obtida. A energia térmica responde por parcela apreciável do custo de transformação associado à pelotização. Num circuito produtivo que inclua a moagem de minério hematítico, o custo de energia térmica pode chegar a valores superiores a $50 \%$ do custo de transformação minério-pelota.

Os minérios hematíticos consomem muito mais calor que os magnetíticos. Estes últimos são oxidados dentro dos fornos de pelotização, através de reação altamente exotérmica. O calor gerado nessa reação, no interior das pelotas, acelera o processamento térmico e reduz o aporte externo de calor, (demandas adicionais de óleo combustível, gás natural, combustível sólido, etc.).

Para minimizar o consumo de calor na pelotização de minérios hematíticos, muitas empresas adicionam combustível sólido às pelotas cruas. A queima desse combustível no interior das pelotas aporta, diretamente, parte do calor necessário ao processo, com um maior rendimento térmico.

O balanço térmico de fornos de pelotização já foi bastante estudado e encontra-se disponível na literatura técnica. (2) Quando analisando o assunto, é importante caracterizar o tipo de minério de ferro e a tecnologia do forno de pelotização, pois estes fatores afetam significativamente os resultados.

O balanço térmico não será tema desta abordagem. Pensa-se que seja mais interessante caracterizar o consumo mínimo teórico de calor para se produzir 1(uma) tonelada de pelotas, a partir de minério hematítico, considerando-se que, majoritariamente, as reservas Brasileiras são desse tipo de minério. Tendo-se os consumos teóricos como referência, é possível analisar, genericamente, o desempenho de fornos de pelotização e a eficiência térmica do processamento de queima das pelotas.

\section{METODOLOGIA - ASPECTOS CONCEITUAIS - PREMISSAS}

Neste trabalho, considera-se que o leitor esteja familiarizado com o processo de pelotização de minério de ferro, principalmente nas etapas de formação da pelota crua (pelotamento) e queima nos fornos de pelotização. ${ }^{(1,3)}$

Sabe-se, então, que, na pelotização, o minério de ferro e aditivos são devidamente beneficiados, misturados, umedecidos e pelotizados em discos ou tambores. Daí, as pelotas cruas obtidas seguem para a etapa de queima nos fornos tipo Traveling Grate ou Grate-Kiln, onde ocorre a consolidação final das pelotas. Nesses fornos, há diferentes zonas de aquecimento-secagem, queima e resfriamento das pelotas. A temperatura máxima atinge valores da ordem de 1300 oC. Na etapa de resfriamento, os gases quentes de exaustão são recuperados e reciclados no processo, o que melhora consideravelmente o rendimento térmico dos fornos. ${ }^{(2,3)}$ 
Para a formação das pelotas cruas, o teor de umidade da mistura de minério de ferro e aditivos deve ser ajustado ao ponto ótimo. Um valor aquém desse ponto conduz à formação de pelotas cruas de qualidade inferior e à perda de produtividade no pelotamento. Por outro lado, um excesso de umidade prejudica a etapa seguinte de queima das pelotas, pois esse excedente tem de ser evaporado, causando aumento do consumo de energia térmica no forno. A rigor, o teor de umidade ótima deveria ser determinado para cada composição de mistura a pelotizar. No entanto, ainda não há ensaios de laboratório padronizados para tal determinação. Porém, existe metodologia experimental desenvolvida por institutos de pesquisa Japoneses, ainda em estágio de avaliação pelos produtores de pelotas.

No processamento térmico das pelotas no interior dos fornos de pelotização, há de se considerar os seguintes fenômenos físico-químicos, dentre outros possíveis:

- Aquecimento e evaporação da umidade das pelotas cruas;

- Desidratação de eventuais compostos com água no estado cristalino, [limonita, Goethita, $\mathrm{Ca}(\mathrm{OH}) 2, \mathrm{Mg}(\mathrm{OH}) 2$, etc.];

- Calcinação de carbonatos, [CaCO3, $\mathrm{MgCO} 3, \mathrm{Ca} . \mathrm{Mg}(\mathrm{CO} 3) 2$, etc.];

- Reações de escorificação para a consolidação cerâmica, (CaO.SiO2, 2CaO.SiO2, $\mathrm{CaO} . \mathrm{Fe} 2 \mathrm{O} 3$, etc.);

- No caso de minério magnetítico ( $\mathrm{Fe} 3 \mathrm{O} 4)$, reação de oxidação para a hematita (Fe2O3), com liberação de calor;

- Aquecimento das pelotas a $1300 \mathrm{oC}$;

- Resfriamento das pelotas de 1300 a 100 oC, e recuperação de todo esse calor para o sistema de queima das pelotas (calor liberado pelas pelotas no resfriamento de 1300 a 100 oC).

No mínimo, esses são os processos que devem ser considerados em cálculos de quantidade teórica de calor para a pelotização de minério de ferro.

As reações de combustível sólido (antracito, coke breeze, etc.), eventualmente adicionado às pelotas cruas, não são consideradas no presente cálculo. Esse aditivo confere energia térmica às pelotas, atuando como uma fonte externa de calor, à semelhança do óleo combustível, gás natural, carvão pulverizado, etc., que são queimados nos queimadores dos fornos de pelotização. É evidente que, em se tratando de calcular o balanço térmico do forno de pelotização, esse combustível sólido teria de ser considerado.

Para o desenvolvimento do cálculo teórico da quantidade de calor para a produção de 1 t de pelota queimada, é necessário definir algumas premissas e determinar a composição e montante da mistura dos constituintes da pelota crua. Essa mistura pode ser determinada pelo balanço de massas do sistema de pelotização. 
Nesse desenvolvimento para o minério de ferro hematítico, as seguintes premissas foram consideradas, de forma a possibilitar uma abordagem mais ampla do consumo de calor na pelotização:

- Minério hematítico, com $0,5 \%$ de perda ao fogo;

- As quantidades de calor foram calculadas em relação ao estado padrão: 25 oC ou 298 oK e 1 atm;

- Pelotas contendo $1 \%, 3 \%$ e $5 \%$ de SiO2. Estes tipos de pelotas são representativos da realidade industrial, pois cobrem os campos de produtos para uso em alto-forno e redução direta. Desenvolvidos os cálculos para estas pelotas, é possível executar cálculos similares para qualquer outro tipo;

- Para simplificação, considerou-se a basicidade binária $\mathrm{CaO} / \mathrm{SiO} 2=0,93$, igual à do composto CaO.SiO2. Assim, toda a sílica reage com o $\mathrm{CaO}$, estequiometricamente, não havendo sobras desses compostos. Esta foi a única reação de escória levada em consideração nos cálculos. As outras possíveis foram desprezadas;

- Dosador de $\mathrm{CaO}$ : calcário calcítico. Para simplificação dos cálculos das quantidades de calor, o calcário foi considerado puro, sem contaminação, e contendo $100 \%$ de $\mathrm{CaCO}$. Esta hipótese não tem influência significativa nos resultados;

- Aglomerante: bentonita, no montante de $0,5 \%$ em relação ao peso da mistura a pelotizar;

- Umidade das pelotas cruas: igual a $9 \%$, valor comum em plantas industriais;

- A temperatura das pelotas cruas foi fixada em 35 oC, ou 308 oK, temperatura, típica daquela verificada em plantas industriais de pelotização;

- Estabeleceu-se que as pelotas deveriam ser aquecidas até atingir a temperatura de 1300 oC, ou 1573 oK. No processo Traveling Grate, diferentemente do processo Grate-Kiln, ao final da zona de queima, há uma diferença significativa entre as temperaturas das camadas de topo e fundo do leito de pelotas. Uma boa condição de queima é aquela em que o valor médio dessas temperaturas seja da ordem de 1300 oC;

- Para simplificação dos cálculos relativos ao aquecimento das pelotas a 1300 oC, estabeleceu-se que elas eram compostas de 100\% de $\mathrm{Fe} 2 \mathrm{O} 3$. 
Considerou-se ainda que a fase predominante a 35 oC, no início do aquecimento, era a Hematita alfa e que a 1300 oC era a fase Hematita gama;

- As pelotas processadas foram resfriadas de 1300 a 100 oC (1573 a 373 oK) e, hipoteticamente, todo esse calor foi recuperado para o sistema e totalmente incorporado às pelotas em estágio de queima. Foi considerada a temperatura final das pelotas igual a 100 oC, com predominância da fase $\mathrm{Fe} 2 \mathrm{O} 3$ alfa. Tal temperatura pode ser atingida nos modernos fornos de pelotização.

\section{RESULTADOS E DISCUSSÃO}

Considerando-se as premissas estabelecidas e calculando-se os balanços de massas para os três tipos de pelotas definidos, resultaram as composições das pelotas cruas para a produção de 1 tonelada de pelotas queimadas, com $1 \%, 3 \% \mathrm{e}$ 5\% de $\mathrm{SiO} 2$, conforme mostra a tabela 3.1.

Tabela 3.1 - Composição das pelotas cruas hematíticas para produção de 1 tonelada de pelotas queimadas.

\begin{tabular}{|l|c|c|c|c|c|c|}
\hline \multirow{2}{*}{$\begin{array}{l}\text { COMPONENTE DA PELOTA CRUA } \\
\text { (Premissas - balanço de massas) }\end{array}$} & \multicolumn{2}{|c|}{$1 \%$ SiO2 } & \multicolumn{2}{|c|}{$3 \%$ SiO2 } & \multicolumn{2}{|c|}{$5 \%$ SiO2 } \\
\cline { 2 - 7 } & Peso $(\mathrm{kg})$ & $\%$ & Peso (kg) & $\%$ & Peso (kg) & $\%$ \\
\hline Minério de ferro hematítico - Fe2O3 & 990,38 & 89,0 & 969,76 & 85,8 & 949,15 & 82,7 \\
\hline Calcário calcítico - CaCO3 & 17,17 & 1,5 & 53,65 & 4,7 & 90,14 & 7,9 \\
\hline Bentonita & 5,06 & 0,5 & 5,14 & 0,5 & 5,22 & 0,5 \\
\hline Umidade - H2O & 100,15 & 9,0 & 101,74 & 9,0 & 103,30 & 9,0 \\
\hline Total & 1112,76 & 100,0 & $1.130,29$ & 100,0 & $1.147,81$ & 100,0 \\
\hline
\end{tabular}

Pelos dados apresentados nessa tabela 3.1, verifica-se que ao crescer o teor de sílica da pelota de $1 \%$ para $5 \%$ a quantidade de calcário na pelota crua aumentou significativamente.

Da mesma forma, mesmo com a umidade constante em $9 \%$, houve um acréscimo progressivo do peso de água. Em consequência, o peso total de pelotas cruas para produzir $1 \mathrm{t}$ de pelotas queimadas saltou de 1.112,76 para 1.147,81 $\mathrm{kg}$. Assim, quando se aumenta o teor de sílica da pelota, mantendo-se a basicidade binária constante, há uma progressiva perda de rendimento em massa para a produção de 1 t de pelota.

Isso, naturalmente, acarreta maiores consumos de calor para a calcinação do calcário adicional e para a vaporização do peso de água excedente. Observa-se, 
também, uma progressiva redução no consumo de minério de ferro, haja vista os valores crescentes de sílica e de adição de calcário.

A tabela 3.2 mostra os resultados referentes à quantidade teórica de calor para a produção de 1t de pelotas hematíticas, dentro das premissas estabelecidas. Os cálculos foram realizados, utilizando-se uma planilha Excel da Microsoft, onde o modelo foi construído, baseando-se nos princípios da termodinâmica, termoquímica e nas premissas anteriormente estabelecidas. As etapas e as equações para cálculos das quantidades de calor estão discriminadas nessa tabela 3.2. ${ }^{(4)}$

Considerando-se as premissas estabelecidas e analisando-se os dados da tabela 3.2, poderiam ser feitos os seguintes comentários:

- O consumo teórico de calor de fontes externas para a produção de 1 tonelada de pelotas, considerando-se a recuperação de calor, cresce progressivamente com o aumento do teor de sílica. Para 1\% de SiO2, o consumo é próximo de $76.000 \mathrm{kcal} / \mathrm{t}$ e para $5 \%$ é por volta de $95.000 \mathrm{kcal} / \mathrm{t}$ $(+25 \%)$, conforme mostra a figura 3.1. Dentro da premissa de basicidade constante, estabelecida para os três tipos de pelotas, $(\mathrm{CaO} / \mathrm{SiO} 2=0,93), 0$ crescimento do teor de sílica implica no aumento progressivo do montante de $\mathrm{CaO}$ adicionado às pelotas. Em outras palavras, na necessidade de maior aporte de calor para a decomposição do calcário equivalente ao aumento da basicidade.

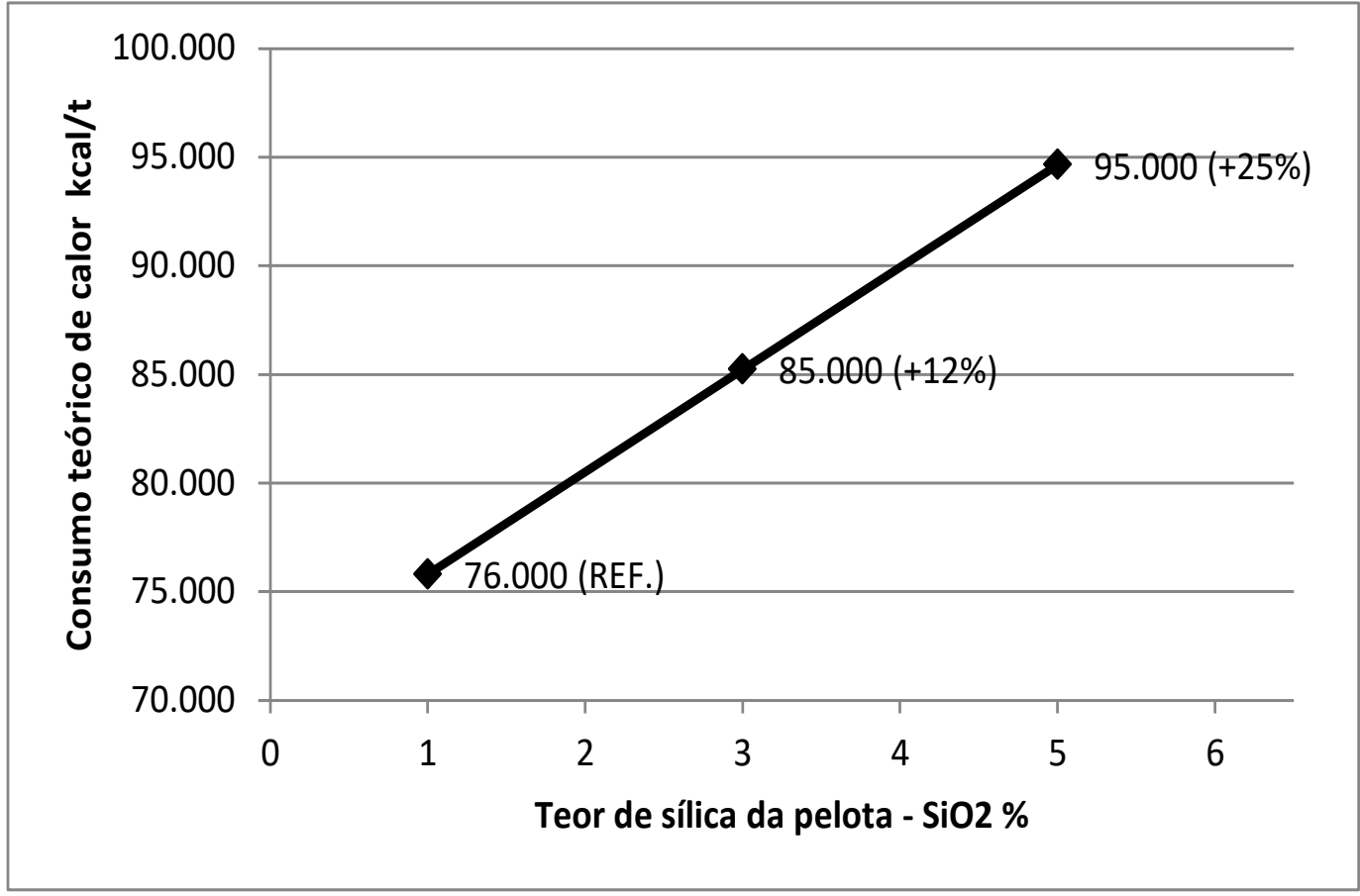

Figura 3.1 - Consumo teórico de calor para a produção de 1 t de pelota hematítica. 
Tabela 3.2 - Cálculo da quantidade teórica de calor para produção de 1 t de pelota hematítica.

\begin{tabular}{|c|c|c|c|}
\hline TEOR DE SÍLICA DA PELOTA - SIO2 \% & 1,00 & 3,00 & 5,00 \\
\hline Basicidade da Pelota - CaO/SiO2 & 0,93 & 0,93 & 0,93 \\
\hline \multicolumn{4}{|l|}{ ETAPAS DO PROCESSAMENTO TÉRMICO DAS PELOTAS } \\
\hline \multicolumn{4}{|l|}{1 - AQUECIMENTO E VAPORIZAÇÃO DA ÁGUA DAS PELOTAS CRUAS COM 9\% DE UMIDADE } \\
\hline Peso da água na pelota crua - do balanço de massas (g) & 100.150 & 101.740 & 103.310 \\
\hline $\mathrm{Mol} \mathrm{H} 2 \mathrm{O}(\mathrm{g})$ & 18,00 & 18,00 & 18,00 \\
\hline No. Moles H2O & $5.563,89$ & $5.652,22$ & $5.739,44$ \\
\hline \multirow{2}{*}{\multicolumn{4}{|c|}{$\begin{array}{l}\text { Aquecimento de } 35 \text { a } 100 \text { oC ou } 308 \text { a } 373 \text { oK; Ental pia da água }=f(T) \text {, sendo } T \text { em oK: } \\
\Delta H(T)=(H T-H 298)=18,04 . T-5379 \mathrm{cal} / \mathrm{mol}\end{array}$}} \\
\hline & & & \\
\hline$\Delta \mathrm{H}(308)=(18,04 \cdot 308-5379) \cdot($ no. moles $) / 1000 \mathrm{kcal}$ & 986,59 & $1.002,25$ & $1.017,72$ \\
\hline$\Delta \mathrm{H}(373)=(18,04 \cdot 373-5379) .($ no. moles $) / 1000 \mathrm{kcal}$ & $7.510,80$ & $7.630,05$ & $7.747,79$ \\
\hline$\Delta \mathrm{H} 1$ aquecimento da água de 35 a $100 \circ \mathrm{oC}=\Delta \mathrm{H} 373-\Delta \mathrm{H} 308 \mathrm{Kcal}$ & 6.524 & 6.628 & 6.730 \\
\hline \multicolumn{4}{|l|}{ Evaporação } \\
\hline$\Delta \mathrm{H}$ (ebulição) - kcal/mol & 9,82 & 9,82 & 9,82 \\
\hline$\Delta \mathrm{H} 2$ de vaporização da água $=\Delta H$ (ebulição). (no. Moles) kcal & 54.637 & 55.505 & 56.361 \\
\hline $\begin{array}{l}\text { 2 - CALCINAÇÃO DO CALCÁRIO - Reação endotérmica } \\
\text { Reação de calcinação: } \mathrm{CaCO} 3=\mathrm{CaO}+\mathrm{CO} 2 \\
\text { Entalpias de Formação desses compostos }-\Delta \mathrm{Ho}(298)-\mathrm{kcal} / \mathrm{mol}\end{array}$ & & & \\
\hline$\Delta \mathrm{HCaCO} 3$ & $-288,40$ & $-288,40$ & $-288,40$ \\
\hline$\Delta \mathrm{HCaO}$ & $-151,60$ & $-151,60$ & $-151,60$ \\
\hline$\Delta \mathrm{HCO} 2$ & $-94,10$ & $-94,10$ & $-94,10$ \\
\hline$\Delta \mathrm{H}$ da reação de calcinação do calcário $=(\Delta \mathrm{HCaO}+\Delta \mathrm{HCO} 2)-\Delta \mathrm{HCaCO}-\mathrm{Kcal}$ (endotérmica) & 42,70 & 42,70 & 42,70 \\
\hline Mol do $\mathrm{CaCO} 3(\mathrm{~g})$ & 100,00 & 100,00 & 100,00 \\
\hline$C C$ - Consumo de calor por g de calcário $=(\Delta \mathrm{H}$ da reação $) /(\mathrm{mol}$ do CaCO3 $) \mathrm{kcal} / \mathrm{g}$ & 0,43 & 0,43 & 0,43 \\
\hline PC - Peso de calcário - do balanço de massas (g) & 17.170 & 53.650 & 90.140 \\
\hline$\Delta \mathrm{H} 3$ de calcinação do calcário $=$ CC.PC kcal & 7.332 & 22.909 & 38.490 \\
\hline $\begin{array}{l}3 \text { - REAÇÃO DE ESCORIFICAÇÃO - CaO.SiO2 - Reação exotérmica } \\
\text { Reação de escorificação: } \mathrm{CaO}+\mathrm{SiO} 2=\mathrm{CaO} . \mathrm{SiO} 2 \\
\text { Entalpias de Formação desses compostos }-\Delta \mathrm{Ho}(298)-\mathrm{kcal} / \mathrm{mol}\end{array}$ & & & \\
\hline$\Delta \mathrm{HCaO}$ & $-151,60$ & $-151,60$ & $-151,60$ \\
\hline$\Delta \mathrm{HSiO} 2$ & $-217,00$ & $-217,00$ & $-217,00$ \\
\hline$\Delta \mathrm{HCaO} . \mathrm{SiO} 2$ & $-390,00$ & $-390,00$ & $-390,00$ \\
\hline$\Delta \mathrm{H}$ da reação de escorificação $=\Delta \mathrm{HCaO} . \mathrm{SiO} 2-(\Delta \mathrm{HCaO}+\Delta \mathrm{HSiO} 2)-\mathrm{Kcal}-$ Reação Exotérmica & $-21,40$ & $-21,40$ & $-21,40$ \\
\hline Mol do SiO2 (g) & 60,09 & 60,09 & 60,09 \\
\hline $\mathrm{CL}=$ Calor liberado pela reação de escorificação por g de SiO2 $=(\Delta \mathrm{H}$ reação $/ \mathrm{mol}$ de SiO2 $)-\mathrm{kcal} / \mathrm{g}$ & $-0,36$ & $-0,36$ & $-0,36$ \\
\hline$\%$ de $\mathrm{SiO} 2$ nas pelotas queimadas - premissas & 1,00 & 3,00 & 5,00 \\
\hline PSiO2 = Peso de SiO2 em 1t de pelotas $(\mathrm{g})$ & 10.000 & 30.000 & 50.000 \\
\hline$\Delta \mathrm{H} 4$ de escorificaçao $=($ CL.PSiO2 $) /$ calor cedido ao sistema de queima kcal & -3.561 & -10.684 & -17.807 \\
\hline \multicolumn{4}{|l|}{4 - AQUECIMENTO DA PELOTA (HEMATITA - Fe2O3) DE 35 a 1300 oC (308 a 1573 oK) } \\
\hline Peso de hematita - premissa - $1 \mathrm{t}$ de pelotas (g) & 1.000 .000 & 1.000 .000 & 1.000 .000 \\
\hline Mol Fe2O3 (g) & 160,00 & 160,00 & 160,00 \\
\hline No. Moles Fe2O3 & $6.250,00$ & $6.250,00$ & $6.250,00$ \\
\hline \multicolumn{4}{|l|}{ Aquecimento de 308 a 1573 oK; Fase alfa --> Fase gama - Entalpia do Fe2O3 = $f(T)$, sendo T em oK: } \\
\hline \multicolumn{4}{|l|}{$\Delta \mathrm{H} \mathrm{Hem}$ alfa $(\mathrm{T})=(\mathrm{HT}-\mathrm{H} 298)=23,49 . \mathrm{T}+(9,30 \cdot \mathrm{T} \cdot \mathrm{T} / 1000)+(3,55.100000 / \mathrm{T})-9021 \mathrm{cal} / \mathrm{mol}$} \\
\hline \multicolumn{4}{|l|}{$\Delta \mathrm{H}$ Hem gama $(\mathrm{T})=(\mathrm{HT}-\mathrm{H} 298)=31,71 \cdot \mathrm{T}+(0,88 \cdot \mathrm{T} \cdot \mathrm{T} / 1000)-8446 \mathrm{cal} / \mathrm{mol}$} \\
\hline$\Delta$ H Hem alfa $(308)=\{[(23,49.308)+(9,30 \cdot 308 \cdot 308 / 1000)+(3,55 \cdot 100000 / 308)-9021] / 1000\}$. (no. Moles) kcal & $1.554,70$ & $1.554,70$ & $1.554,70$ \\
\hline$\Delta$ H Hem gama $(1573)=\{[31,71 \cdot 1573+(0,88 \cdot 1573 \cdot 1573 / 1000)-8446] / 1000\} .($ no moles $) \quad k c a l$ & $272.570,25$ & $272.570,25$ & $272.570,25$ \\
\hline$\Delta \mathrm{H} 5$ de aquecimento da pelota $=\Delta \mathrm{H}$ Hem gama $(1573)-\Delta \mathrm{H}$ Hem alfa (308) kcal & 271.016 & 271.016 & 271.016 \\
\hline \multicolumn{4}{|l|}{5 - RECUPERAÇÃO DE CALOR DAS PELOTAS - RESFRIAMENTO DE 1300 a 100 oC (1573 a 373 oK) } \\
\hline \multicolumn{4}{|l|}{ Resfriamento das pelotas de 1573 a 373 oK; Fase gama --> Fase alfa: } \\
\hline$\Delta$ H Hem gama $(1573)=\{[31,71 \cdot 1573+(0,88 \cdot 1573 \cdot 1573 / 1000)-8446] / 1000\} .($ no moles $) \quad \mathrm{kcal}$ & $272.570,25$ & $272.570,25$ & $272.570,25$ \\
\hline$\Delta$ H Hem alfa $(373)=\{[(23,49.373)+(9,30 \cdot 373 \cdot 373 / 1000)+(3,55 \cdot 100000 / 373)-9021] / 1000\}$. (no. Moles) kcal & $12.415,08$ & $12.415,08$ & $12.415,08$ \\
\hline$\Delta \mathrm{H6}$ de resfriamento das pelotas $/$ calor recuperado $=\Delta \mathrm{H}$ Hem alfa (373) $-\Delta \mathrm{H}$ Hem gama (1573) kcal & -260.155 & -260.155 & -260.155 \\
\hline \multicolumn{4}{|l|}{6 - QUANTIDADE TEÓRICA DE CALOR PARA QUEIMA DE 1t DE PELOTAS } \\
\hline $\begin{array}{l}\text { 6.1 - Sem recuperação de calor das pelotas queimadas (kcal/t): } \\
\Delta \mathrm{H}=\Delta \mathrm{H} 1+\Delta \mathrm{H} 2+\Delta \mathrm{H} 3+\Delta \mathrm{H} 4+\Delta \mathrm{H} 5\end{array}$ & 335.947 & 345.373 & 354.790 \\
\hline $\begin{array}{l}\text { 6.2 - COM RECUPERAÇÃO DE CALOR DAS PELOTAS AO FINAL DA QUEIMA oC (kcal/t): } \\
\Delta \mathrm{H}^{\prime}=\Delta \mathrm{H} 1+\Delta \mathrm{H} 2+\Delta \mathrm{H} 3+\Delta \mathrm{H} 4+\Delta \mathrm{H} 5+\Delta \mathrm{H} 6\end{array}$ & $\begin{array}{c}75.792 \\
\text { (Referência) }\end{array}$ & $\begin{array}{l}85.218 \\
(+12 \%)\end{array}$ & $\begin{array}{l}94.635 \\
(+25 \%)\end{array}$ \\
\hline
\end{tabular}


- Caso não houvesse a recuperação de calor no resfriamento das pelotas, o consumo teórico de calor subiria consideravelmente, passando de 76.000 $\mathrm{kcal} / \mathrm{t}$ para $336.000 \mathrm{kcal} / \mathrm{t}$ para as pelotas com 1\% de SiO2, e de $95.000 \mathrm{kcal} / \mathrm{t}$ para $355.000 \mathrm{kcal} / \mathrm{t}$ no caso das pelotas com $5 \%$ de SiO2. A figura 3.2 mostra como a recuperação de calor no resfriamento das pelotas é fundamental, para que se tenha menor demanda de calor de fontes externas (combustível sólido, óleo combustível, gás natural, etc.). Isso mostra a importância da recuperação de calor, no processo industrial. Note-se que na sinterização convencional de finos de minério de ferro não há recuperação de calor e, por essa razão, os consumos de energia térmica são elevadíssimos, em comparação com a pelotização.

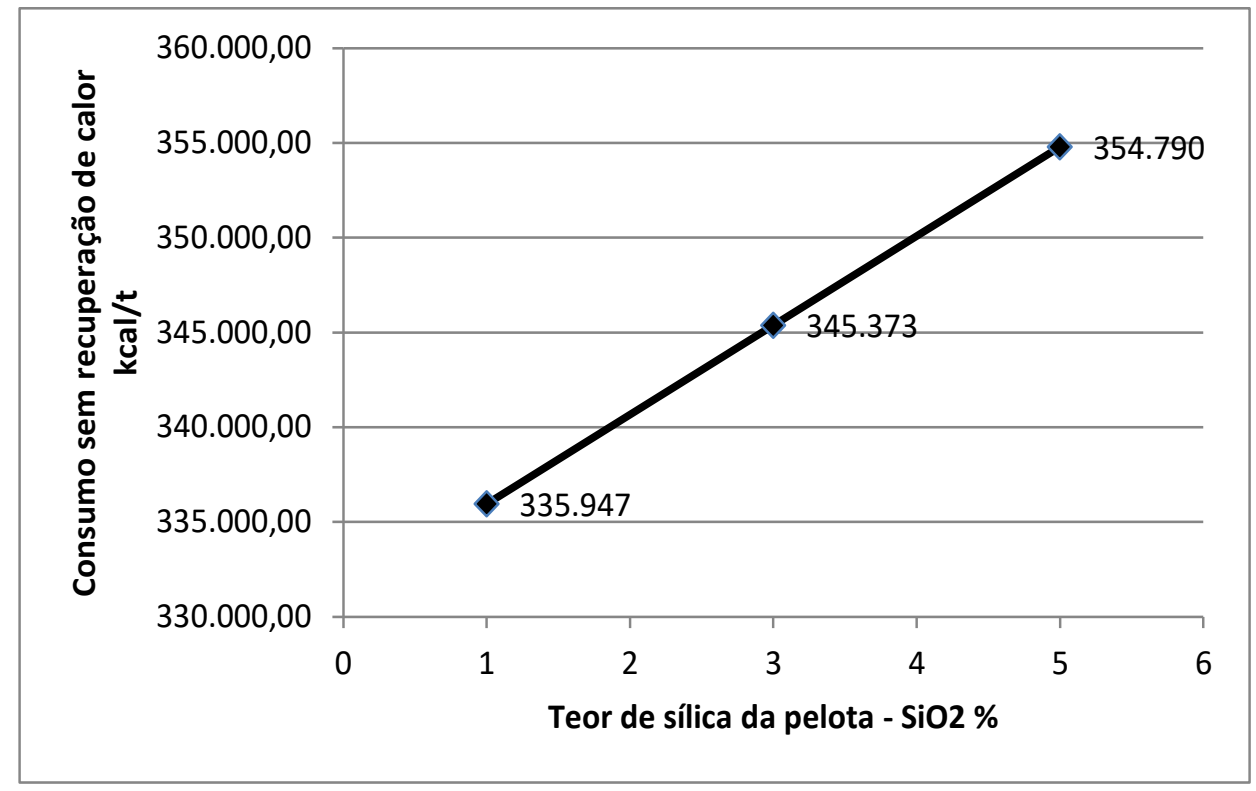

Figura 3.2 - Consumo teórico de calor, sem recuperação no resfriamento das pelotas.

- Para vaporizar a umidade das pelotas cruas, demanda-se grande quantidade de calor. Essa parcela representa mais de $60 \%$ do calor teórico necessário para a produção de pelotas, considerando-se a recuperação integral do calor no resfriamento e sua incorporação total às pelotas. Os dados da tabela $3.2 \mathrm{e}$ a figura 3.3 mostram esse fato. Por esta razão, nas plantas industriais, devese estabelecer um controle rígido do teor de umidade das pelotas cruas, buscando-se trabalhar no ponto ótimo. Como os minérios de ferro são diferentes e há vários tipos de pelotas, deve-se estabelecer esse teor ótimo de umidade, para cada mistura a pelotizar. Vale mencionar que, para cada $1 \%$ de umidade adicional das pelotas cruas, há um incremento no consumo de calor de cerca de $6.000 \mathrm{kcal}$. 


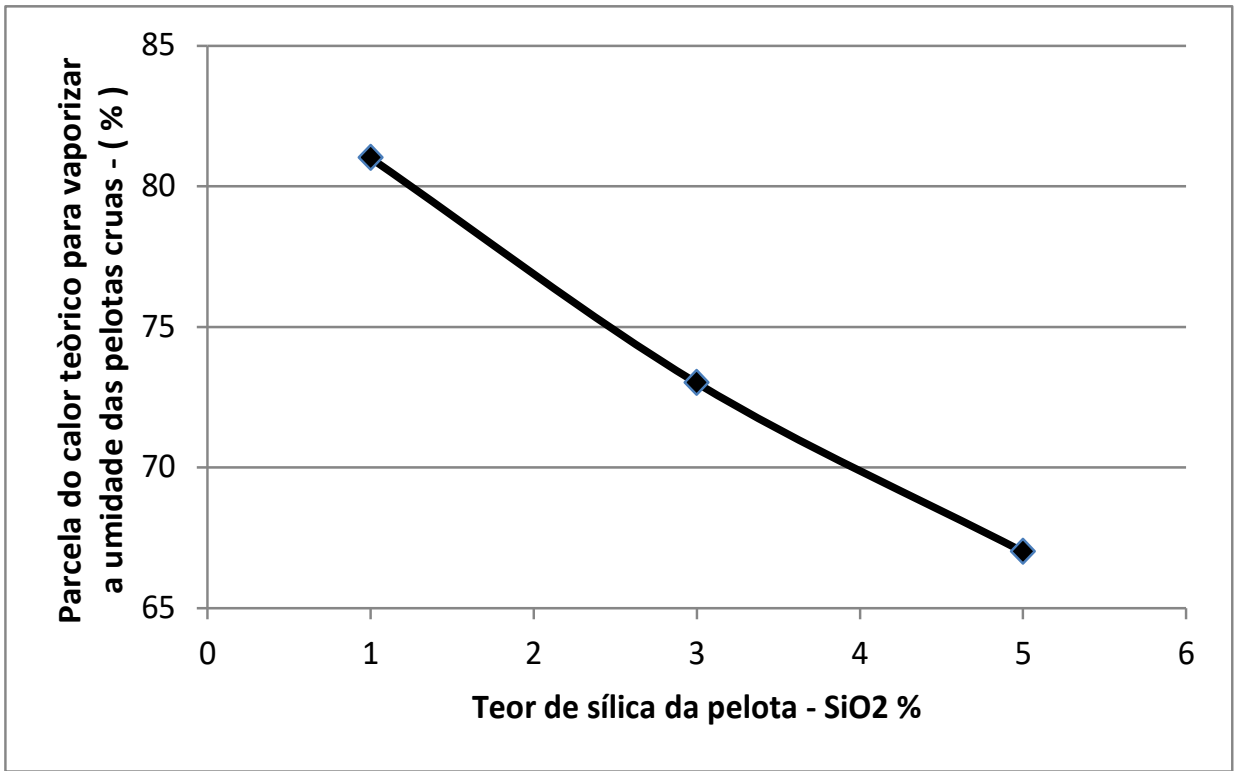

Figura 3.3 - \% do calor teórico necessário para vaporizar a umidade das pelotas cruas.

- Os fornos industriais de pelotização de minérios hematíticos apresentam consumos de calor bastante elevados, em relação ao mínimo teórico, com recuperação de calor. Dependendo da eficiência dos fornos, os consumos podem variar na faixa de 180.000 a $350.000 \mathrm{kcal} / \mathrm{t}$ de pelotas. A eficiência no uso da energia térmica $(\boldsymbol{\mu})$ poderia ser avaliada, indiretamente, pela relação percentual entre o consumo teórico de calor (com recuperação) e o consumo total, verificado numa planta industrial. Dentro deste conceito, curvas de eficiência, em função do teor de sílica das pelotas queimadas, poderiam ser construídas, conforme mostra a figura 3.4.

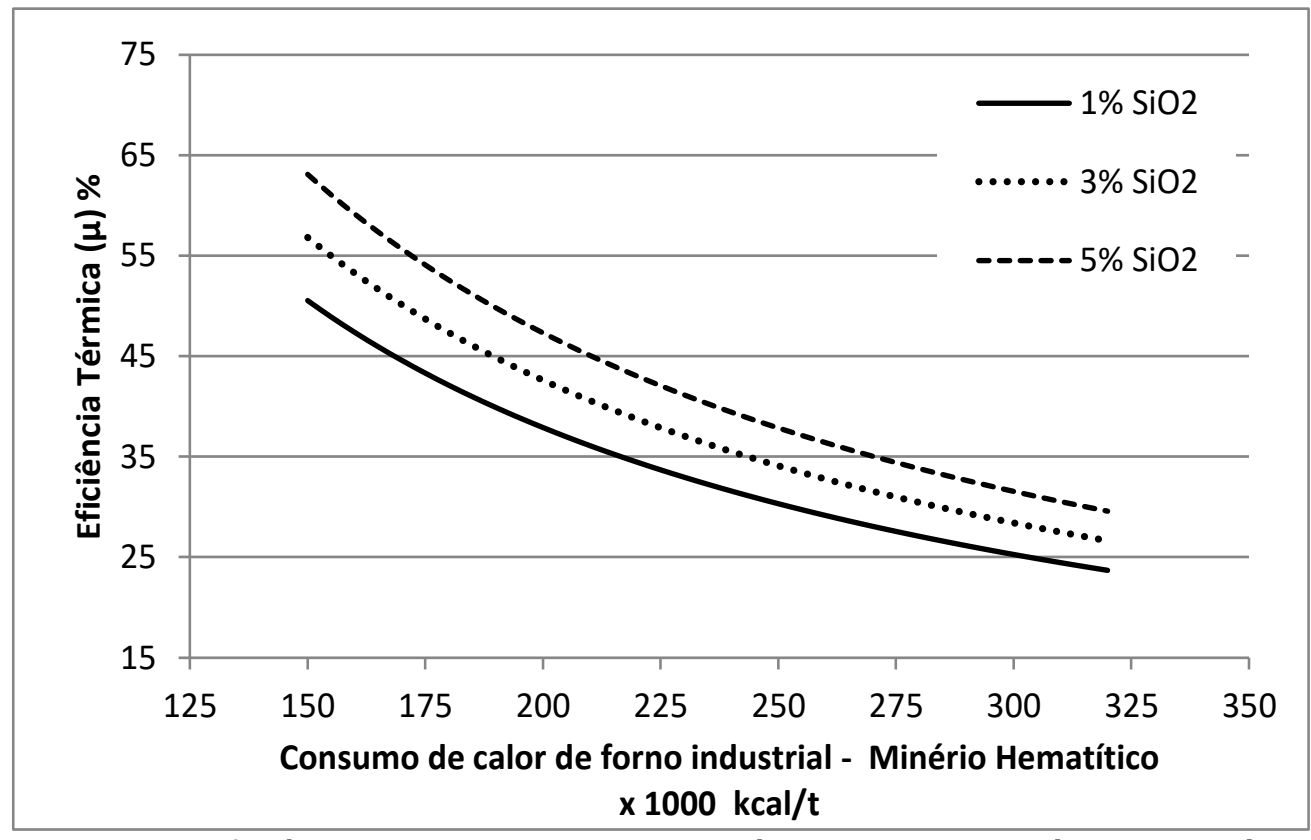

Figura 3.4 - Eficiência no uso da energia térmica para minério hematítico. 
Dados conhecidos da indústria têm mostrado que a eficiência térmica é relativamente baixa, situando-se na faixa de 25 a $40 \%$ para minérios hematíticos, dependendo das condições operacionais. Há relatos de fornos de classe mundial que produzem pelotas hematíticas do tipo redução direta (1\% de SiO2) com consumo de calor da ordem de170.000 kcal/t. Plotando-se esse valor no gráfico da figura 3.4, verifica-se que a eficiência térmica desses fornos é da ordem de 45\% (benchmark). Extrapolando-se essa mesma eficiência de $45 \%$ para as pelotas com 3 e $5 \%$ de SiO2, constata-se que os consumos de calor correspondentes teriam de ser iguais a $190.000 \mathrm{kcal} / \mathrm{t}$ e $210.000 \mathrm{kcal} / \mathrm{t}$, respectivamente (valores ainda não atingidos nas operações industriais com hematita). Assim, há muita oportunidade de melhoria de processo na operação dos fornos de pelotização. Da análise geral do tema energia térmica, fica a questão:

Seria possível atingir eficiência térmica de 50\% nos fornos industriais operando com hematita?

\section{$\mu \%=$ (calor teórico com recuperação /calor consumido no forno $) \times 100$}

- Um ponto importante a ser observado, e que tem grande impacto na eficiência térmica, é a temperatura final das pelotas, após o seu resfriamento nos fornos de pelotização.

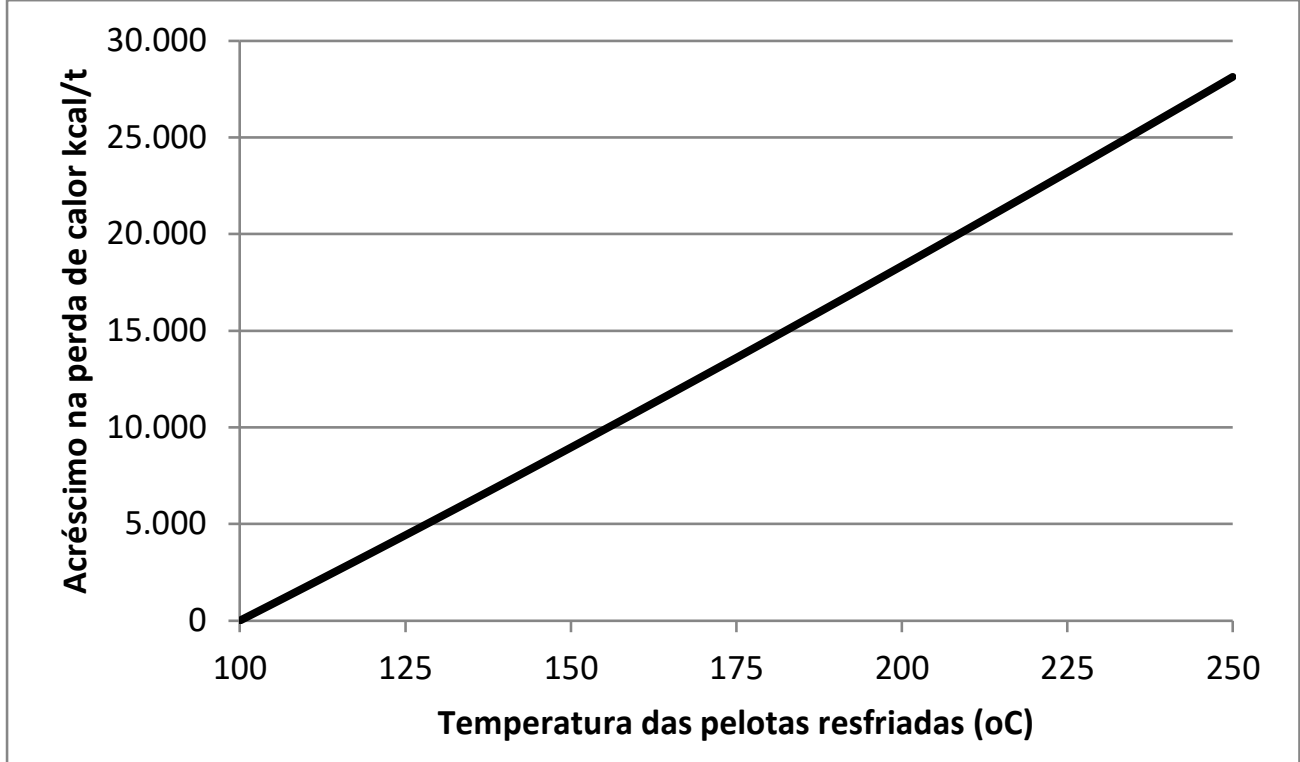

Figura 3.5 - Acréscimo na perda de calor em função da temperatura final das pelotas.

Mesmo após resfriadas, as pelotas carregam uma grande quantidade de calor. Quanto maior a temperatura, menor é a eficiência do resfriamento no forno (recuperação de calor) e maior é a perda de energia térmica para o meio ambiente, já que as pelotas são estocadas em pátios abertos. Esse parâmetro, temperatura final das pelotas, deve ser continuamente monitorado e minimizado na operação dos fornos industriais, para reduzir as perdas de 
calor e melhorar a eficiência térmica. De acordo com as premissas adotadas neste desenvolvimento, a temperatura de referência final das pelotas, após resfriamento, foi de 100 oC. Tendo-se em vista esta condição, foram desenvolvidos cálculos das perdas adicionais de calor, correspondentes aos casos em que as pelotas fossem resfriadas a temperaturas superiores a 100 oC. A figura 3.5 mostra como a minimização da temperatura final das pelotas é fundamental para o controle das perdas de energia térmica nos fornos de pelotização.

- Quando se analisam os fornos industriais de pelotização de minério de ferro hematítico, verifica-se que a eficiência térmica é relativamente baixa. Assim, há de se estabelecer um controle do processo, de forma que as perdas de calor sejam minimizadas e a recuperação de calor no resfriamento das pelotas seja maximizada.

A dosagem de combustível sólido às pelotas cruas melhora a eficiência térmica, haja vista que o calor da combustão é gerado no interior das próprias pelotas. Assim, deve-se procurar trabalhar com a máxima dosagem desse combustível sólido. Há plantas industriais de pelotização de minério hematítico que operam com a adição de 1,25\% de carbono fixo, sendo referência nessa área (benchmark). A temperatura das pelotas cruas também deveria ser considerada nesses estudos de melhoria do rendimento térmico. Temperaturas mais altas aceleram as etapas de secagem no forno.

Nos fornos tipo Traveling Grate, parte da produção de pelotas é reciclada para a formação das camadas de fundo e lateral da grelha. A altura e a largura dessas camadas devem ser reduzidas ao máximo possível, pois essas pelotas perdem algum calor para o meio ambiente, no trajeto de retorno ao forno (recirculação). Algumas plantas industriais já eliminaram a camada lateral e trabalham com camada de fundo de apenas $5 \mathrm{~cm}$.

As câmaras dos fornos de pelotização trabalham com pressão relativa levemente negativa (vácuo), de forma que há continuamente um fluxo de ar frio do ambiente para o interior do forno. Isto é, também um fator de perda de eficiência térmica. Assim, essas pressões relativas devem ser monitoradas e mantidas em valores o mais próximo possível de zero.

Os fornos de pelotização do tipo Grate-Kiln (GK) possuem 3 reatores, ao invés de um único, como no processo Traveling Grate (TG). O tempo de residência total no GK é da ordem de $70 \mathrm{~min}$, mais que o dobro dos modernos fornos TG. Estes dois fatores contribuem para que as perdas térmicas e o consumo de calor no processo GK sejam maiores que os correspondentes valores verificados no processo TG.

Nos estudos para otimização da eficiência térmica dos fornos, há de se considerar o tamanho das pelotas e a porosidade do leito como fatores críticos. As pelotas menores têm maior superfície específica (m2/t), favorecendo o contato com os gases quentes nas fases de aquecimento e queima, e com o ar frio na etapa de resfriamento. Assim, aceleram as trocas 
de calor por convecção gás quente/pelota e pelota quente/ar frio, aumentando os rendimentos no aquecimento (absorção do calor) e no resfriamento das pelotas (recuperação de calor).

Os fluxos de gases através das pelotas dependem da porosidade do leito. Para melhorar essa porosidade, deve-se estreitar a faixa granulométrica das pelotas, diminuindo-se a amplitude dos tamanhos. Sendo a convecção a principal forma de transmissão de calor entre as pelotas e os gases, há muita ineficiência nesse processo, o que implica em perdas consideráveis de calor, seja através das pelotas queimadas que deixam o forno, seja através dos gases quentes de exaustão nas chaminés (calor sensível).

Desta forma, essas e outras perdas de calor devem ser estudadas mais detalhadamente:

- Perdas nos gases quentes de exaustão nas chaminés;

- Perdas por transmissão de calor através das paredes refratárias e dutos do forno;

- Fuga de gases quentes para o meio ambiente;

- Entrada de ar frio por problemas em selagens e pressão negativa nas câmaras do forno (vácuo);

- Eventual entrada de água;

- Perda de calor na recirculação das camadas de fundo e lateral (processo Traveling Grate);

- Perdas de calor através dos carros de grelha (temperaturas de saída/reentrada no forno);

- Entrada de ar frio para atomização de queimadores;

○ Etc.

Além dos aspectos técnico-econômicos dessas perdas térmicas, vale ressaltar que todo o calor perdido nos fornos de pelotização vai para o meio ambiente e que maiores perdas significam maiores emissões de $\mathrm{CO} 2, \mathrm{SOx}$, NOx, etc.

Para sintetizar o que foi discutido sobre energia térmica em fornos de pelotização de minérios hematíticos e sobre as perdas de calor para o meio ambiente, construiu-se o diagrama mostrado na figura 3.6. 


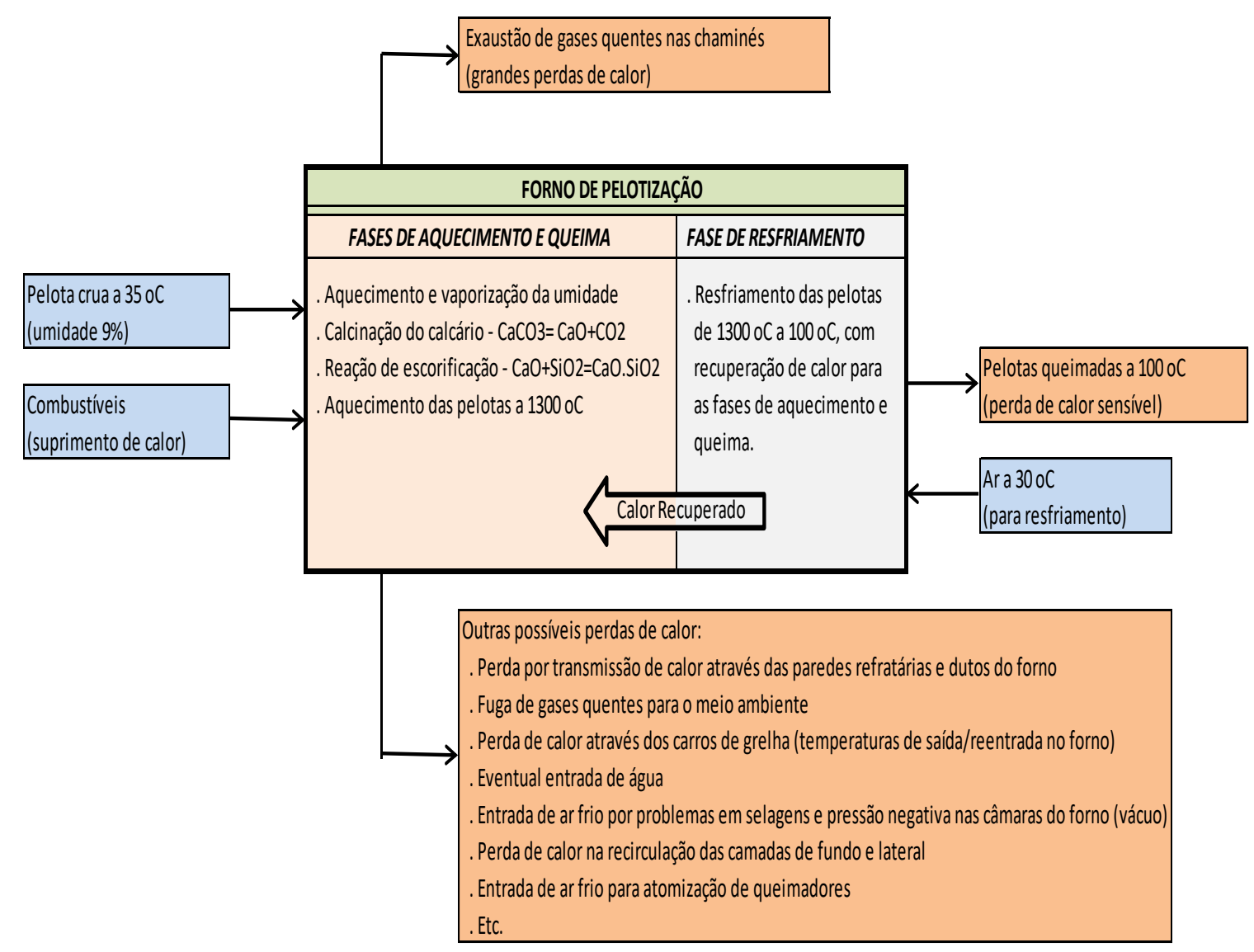

Figura 3.6 - Diagrama genérico de um forno de pelotização evidenciando os fluxos de calor e fatores de perdas térmicas

\section{CONCLUSÃO}

A pelotização de minério de ferro hematítico demanda grande quantidade de calor, o qual é suprido por combustíveis de fontes não renováveis, tais como: gás natural, óleos combustíveis derivados de petróleo, carvão mineral, etc. No Brasil, há um grande parque pelotizador instalado, com capacidade da ordem de 85 Mta de pelotas. Operando a plena carga, a demanda anual de energia térmica seria em torno de 20.000.000 Gcal, ou o equivalente a 2.000.000 t de óleo combustível, quantidade esta superior à demanda anual de muitos estados Brasileiros e, até mesmo, de alguns países.

Conforme mostrado neste trabalho, a eficiência térmica dos fornos de pelotização é relativamente baixa, quando se consideram, como referência, os consumos teóricos de calor para os diferentes tipos de pelotas. Sendo assim, há muitas oportunidades de melhoria do processamento de queima das pelotas hematíticas e, por conseguinte, dos fornos industriais, no sentido de minimizar os consumos de calor. 


\section{REFERÊNCIAS}

1 Mourão, J. M. - The Growing Importance of Pelletizing for Iron Ore and Iron Production. Paper presented at the $2^{\text {nd }}$ International Symposium on Iron Ore, sponsored by ABM Associação Brasileira de Metalurgia e Materiais - September $22^{\text {nd }}-26^{\text {th }}$, Brazil, 2008.

2 Machado, A. F. e Souza, R. P. - Balanço Térmico de um Forno de Pelotização de Minério Hematítico. Trabalho apresentado no Simpósio sobre Redução de Minério de Ferro, promovido pela COMIN da ABM, em Vitória ES, 1975.

3 Ball, D. F. et alii - Agglomeration of Iron Ores, book published by Heinemann Educational Books Limited, London, $1^{\text {st }}$ Edition, 1973.

4 Dados Termodinâmicos para Metalurgistas - Livro publicado pelo Departamento de Engenharia Metalúrgica e de Materiais - Universidade Federal de Minas Gerais UFMG. 